\title{
Influence of the speech-language pathologist's orientation on maximum phonation times
}

\author{
Amanda Rissetti Coelho(1) \\ Larissa Thais Donalonso Siqueira ${ }^{(1)}$ \\ Congeta Bruniere Xavier Fadel(1) \\ Marcelo de Oliveira Rosa(2) \\ Ana Paula Dassie-Leite ${ }^{(1)}$
}

(1) Universidade Estadual do Centro-Oeste/ UNICENTRO, Irati, Paraná, Brasil.

(2) Universidade Tecnológica Federal do Paraná/UTFPR, Curitiba, Paraná, Brasil.

Conflict of interests: Nonexistent

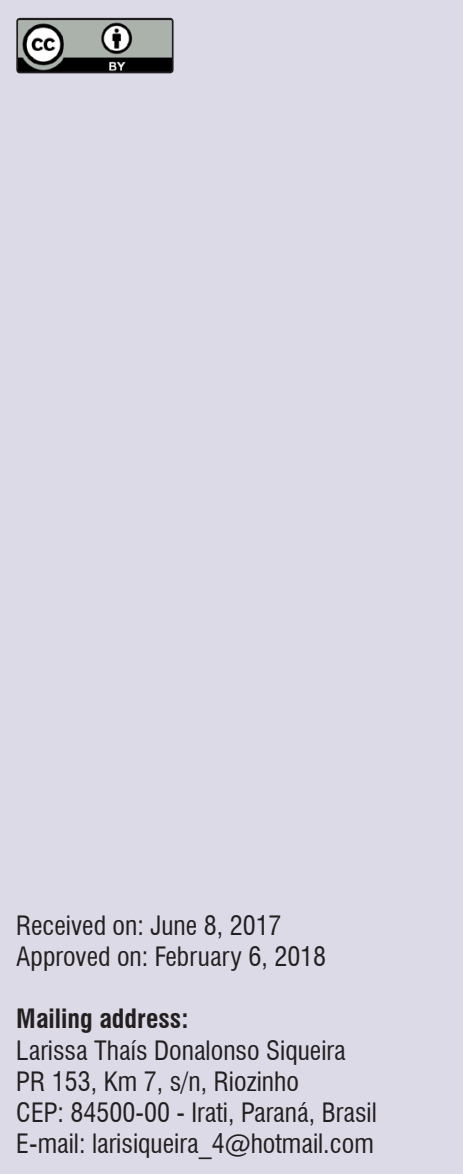

\section{ABSTRACT}

Purpose: to compare the results of maximum phonation times (MPTs) under two different forms of speech-language pathology orientation to extract these measures.

Methods: 60 women between 17 and 23 years divided equally into two groups participated: Study Group (SG) - that performed the task under the two forms of orientation (traditional orientation and with control request of the air outlet); and the Control Group (CG) - which carried out the task in a single form of orientation (traditional one). The procedures performed comprised the extraction of MPT in the vowels $/ \mathrm{a} /$, /i/ and $/ \mathrm{u} /$, the fricatives $/ \mathrm{s} /$ and $/ \mathrm{z} /$ and numbers counting. The data were tabulated and statistically analyzed $(p<0.05)$.

Results: by comparing the two groups at the first instant of the MPT emissions, no statistically significant differences were found. However, when the second instant was compared, there were differences in most emissions, which indicates that the air control request promotes the increase of MPTs.

Conclusion: the way the speech-language pathologist guides the performance of the maximum phonation times, during the evaluation of these measures, requesting the individual tomaximally control air exit, modifies the result of the extraction of the temporal measures of the voice, which must be considered in the daily vocal clinical practice.

Keywords: Voice Disorders; Dysphonia; Respiration; Voice; Phonation 


\section{INTRODUCTION}

Vocal disturbances are understood as deviations that change voice intelligibility and effectiveness, and they can be manifested in several ways, such as changes in the vocal intensity, frequency and quality. Such disturbances can be caused by trauma/disorders in the laryngeal and respiratory functionings or in the vocal tract ${ }^{1}$.

In the speech-language pathology clinic, an assessment is performed to better investigate vocal disorders. Such a procedure is very important in the clinical diagnosis of dysphonias since the data obtained in it directs the therapeutic approach to be taken ${ }^{2}$. The objective of voice speech assessment is to understand, describe and identify the subject's vocal behavior, identify the causal factor of a possible dysphonia, and describe the observed voice characteristics. Such evaluation consists of several procedures such as anamnesis, auditory-perceptual evaluation, acoustical analysis and self-assessment ${ }^{2}$.

Among these speech-language pathology procedures of assessment, several vocal measurements are gathered and the extraction of the maximum phonation times (MPTs) among them. Although technically considered as acoustic measurements, MPTs are usually gathered during the vocal behavior clinical assessment due to the easiness and practicality of their acquisition ${ }^{3}$. This measurement corresponds to the maximum time that the subject can sustain a vocalization during a single expiration, in usual tone and frequency ${ }^{3-6}$. Therefore, it is a test that indicates the efficiency of both glottal closure and respiratory system besides observing the evolution of dysphonic subjects in speech-language pathology ${ }^{2}$.

The MPT extraction is conducted in an objective, fast, and easy way, being routinely applied to dysphonic subjects $^{7}$, and is also considered a highly reliable evaluation ${ }^{8}$. To perform such extraction it is necessary to time the emission durations of vowels (usually /a/, /i/, $/ \mathrm{u} /$ ) with a subsequent calculation of their average as well as the number counting durations. The choice for the vowels /a/, /i/ and /u/ is given by the fact that they correspond to the polygon of vowels ${ }^{2}$. In addition to the aforementioned emissions, the MPT of the fricatives $/ \mathrm{s} /$ and $/ \mathrm{z} /$ is also collected during the extraction of the temporal measurements with subsequent calculation of their relationships. Authors point out that the MPTs show the control between the aerodynamic forces of the pulmonary current and the myoelastic forces of the larynx ${ }^{9}$.
Some divergences are observed regarding the MPT extraction in clinical practice, which may be related to the large variability of the normality parameters described in literature ${ }^{3,7}$, such as the position of the subjects during such extraction ${ }^{6,10,11}$, and the presence or not of lesions in the vocal folds, which would hamper the glottal closure and reduce MPTs ${ }^{5}$. It is also observed that studies indicate that the subject's age can affect MPTs, reducing them ${ }^{10}$ or not ${ }^{6,12}$.

Moreover, in daily clinical practice of a speechlanguage pathologist, inconsistency has been observed between data from literature and results obtained in the evaluations, which is one of the aspects that motivated to carry out the present study. It has also been verified that when asking some patients to control the airflow during the expiration longer times has been generated, although until now any scientific data on this subject has not been obtained. Some studies even report the order given by the evaluator at the instant of MPT extraction, but it is a variable aspect among the studies and none of them has so far investigated the influence that may cause the values obtained from phonatory measurements.

Therefore, a hypothesis raised for these aforementioned divergences is the form of guidance given by the speech-language pathologist to the patient in order to perform the phonatory task that could affect the obtained results. It is believed that a specific guidance about the need for controlling the airflow, aiming for a longer emission, could probably make a difference in the collected MPT data

To verify this hypothesis, we compared two different ways for the clinician to guide the patient at the instant of evaluation of MPT measurements: traditional guidance and the one with airflow control. We hope that the results obtained in this study contribute to improve of the speech-language pathology guidance during the evaluation of the measure of maximum phonation times.

Thus, the objective of this study was to compare the results of the maximum phonation times in two distinct methods of speech-language pathology guidance in extracting these measures.

\section{METHODS}

This is a cross-sectional observational study, in which two forms of orientations were analyzed in order to extract the maximum phonation times of the female subjects. The project was approved by the Research Ethics Committee of Universidade Estadual do 
Centro-Oeste - UNICENTRO under number 1,213,297 and all subjects signed an Informed Consent Term (TCLE).

Subjects were 60 women aged between 17 and 23 years (the mean age was 19 years) who were equally divided into two groups: Study Group (SG) - who performed the task under two forms of speechlanguage pathology guidance (traditional orientation; and the orientation to control the airflow); and Control Group (CG) - who performed the task under a single form of speech-language pathology guidance (traditional orientation) twice.

The two different forms of guidance for extracting the maximum phonation times (MPT) were:

Traditional orientation $2,10,13,14$ : Women were instructed to deeply inhale and to emit the requested sound for as long as they could. Exact guidance given to the subject: "Take a deep breath and make the sound of the letter /a/ for as long as you can"

Orientation involving airflow control: The women were instructed to deeply inhale and to emit the requested sound for as long as they could, by controlling the airflow. Exact guidance given to the subject: "Take a deep breath and make the sound of the letter /a/ for as long as you can, controlling as much as possible the airflow."

The inclusion criteria for this study were: women aged between 17 and 23 years (due to the convenience of gathering on a university campus), no spoken and (or) sung voice professionals, with no vocal complaints, and adapted vocal quality observed in vocal screening, performed by a voice-specialized speech-language pathologist. Exclusion criteria were: no neurological changes, no respiratory changes in upper and lower airways, and had performed previous speech therapy for voice problems.

In order to obtain the MPTs, a chronometer was handled by another speech-language pathologist outside to the study, considering minimizing the gathering bias by the researcher herself, who knew the objective in the study and had a hypothesis regarding the possible study results. The speech-language pathology volunteer was instructed to start the timer at the beginning of the emission and stop it immediately after its completion. This researcher, therefore, had the function to register the obtained values of MPTs and to guide the subject in the execution of the speech test. The chronometer was selected as a tool to extract the measures of MPTs since the literature has indicated no differences in the way of gathering measurements conducted by both experienced and newly trained evaluators as well as with the assistance of computer software.

All the women were evaluated in a silent, acoustically treated room, with noise below 50 decibels (dBs), and remained seated with an upright posture. The procedures performed comprised: MPT extraction of vowels $/ a /, / i /$ and $/ \mathrm{u} /$, of fricatives $/ \mathrm{s} /$ and $/ \mathrm{z} /$, and of number counting by means of a Casio Stopwatch HS-3 digital chronometer.

Initially, the SG women performed the task under the traditional orientation and the values were registered by the researcher. After ten minutes, the SG women performed the task under guidance involving airflow control, with new results extracted and registered. The CG women performed the task twice under the traditional orientation with a ten-minute interval between the executions as well.

It is important to emphasize that all women from both groups were instructed to perform the emissions in usual and effortlessly phonation at both instants of evaluation.

The data were tabulated in an Excel spreadsheet and two extra calculations were performed in addition to the values from vowels $/ \mathrm{a} /, \mathrm{li} /, / \mathrm{u} /$, consonants $/ \mathrm{s} /$ and $/ z /$ and number counting: The value of the mean of the vowels $/ \mathrm{a} /, \mathrm{li} /, / \mathrm{u} /$ and the ratio between the consonants $/ \mathrm{s} /$ and $/ \mathrm{z} /$.

Statistical analysis included the following tests: Wilcoxon test, Student's t test and Mann-Whitnney test in order to compare the two emissions performed in each group as well as to compare both groups. For all analyzes, a significance level of $95 \%$, or 0.05 , was adopted.

\section{RESULTS}

For all the collected samples, the results showed that there are differences between the MPTs obtained in the two ways of guidance given to the SG. When the subject is instructed to perform an emission by controlling the airflow, an increase in the MPT values is observed for all emissions (Table 1). 
Table 1. Comparison of the two instants of Maximum Phonation Time extraction in different guidances (traditional orientation -1 and orientation with airflow control -2) in the Study Group - SG

\begin{tabular}{|c|c|c|c|c|c|}
\hline \multirow{2}{*}{ Emissions } & \multicolumn{4}{|c|}{ Values } & \multirow{2}{*}{ p } \\
\hline & $n$ & Mean & Median & SD & \\
\hline MPT /a/ 1 & 30 & 11.85 & 10.62 & 3.68 & \multirow{2}{*}{0.000} \\
\hline MPT /a/ 2 & 30 & 15.56 & 15.23 & 4.64 & \\
\hline MPT /i/ 1 & 30 & 12.55 & 12.64 & 3.37 & \multirow{2}{*}{0.000} \\
\hline MPT /i/ 2 & 30 & 18.77 & 17.82 & 5.66 & \\
\hline MPT /u/ 1 & 30 & 13.1 & 12.22 & 4.08 & \multirow{2}{*}{0.000} \\
\hline MPT /u/ 2 & 30 & 18.13 & 17.3 & 5.06 & \\
\hline Mean vowels 1 & 30 & 12.5 & 12.04 & 3.22 & \multirow{2}{*}{0.000} \\
\hline Mean vowels 2 & 30 & 17.52 & 16.35 & 4.71 & \\
\hline MPT /s/ 1 & 30 & 13.77 & 12.34 & 5.76 & \multirow{2}{*}{0.000} \\
\hline MPT /s/ 2 & 30 & 18.33 & 17.52 & 8.08 & \\
\hline MPT /z/ 1 & 30 & 12.45 & 12.3 & 4.48 & \multirow{2}{*}{0.000} \\
\hline MPT /z/ 2 & 30 & 18 & 17 & 5.81 & \\
\hline MPT /\#/ 1 & 30 & 16.37 & 16.32 & 5.44 & \multirow{2}{*}{0.000} \\
\hline MPT /\#/ 2 & 30 & 19.89 & 18.97 & 5.86 & \\
\hline
\end{tabular}

Wilcoxon test $(p<0,05)$. Legend: $S D=$ standard deviation; MPT = Maximum Phonation Time

1 - Traditional orientation

2 - Orientation with airflow control

Table 2 presents data regarding the two MPT extractions performed over the $\mathrm{CG}$ in which only the traditional orientation was given to the subjects. In this group, it was observed that only few emissions presented higher values when a second MTP extraction was performed.

Table 2. Comparison of the two instants of Maximum Phonation Time extraction under the same guiding form (traditional orientation in the two instants of extraction) in the Control Group - CG

\begin{tabular}{|c|c|c|c|c|c|}
\hline \multirow{2}{*}{ Emissions } & \multicolumn{4}{|c|}{ Valores } & \multirow{2}{*}{$p$} \\
\hline & $\mathrm{n}$ & Mean & Median & SD & \\
\hline MPT /a/ 1 & 30 & 12.98 & 12.97 & 3.22 & 010 \\
\hline MPT /a/ 2 & 30 & 13.66 & 13.5 & 3.59 & 0.180 \\
\hline MPT /i/ 1 & 30 & 14.05 & 13.37 & 3.56 & \\
\hline MPT /i/ 2 & 30 & 14.73 & 13.17 & 4.84 & 0.200 \\
\hline MPT /u/ 1 & 30 & 13.81 & 12.54 & 3.81 & \\
\hline MPT /u/ 2 & 30 & 15.54 & 14.47 & 4.54 & 0.000 \\
\hline Mean vowels 1 & 30 & 13.61 & 13.31 & 3.10 & \\
\hline Mean vowels 2 & 30 & 14.62 & 14.08 & 4.03 & 0.010 \\
\hline MPT /s/ 1 & 30 & 13.05 & 11.95 & 4.19 & \\
\hline MPT /s/ 2 & 30 & 14.00 & 12.61 & 4.62 & 0.150 \\
\hline MPT /z/ 1 & 30 & 12.60 & 11.46 & 4.85 & \\
\hline MPT /z/ 2 & 30 & 14.52 & 11.61 & 5.76 & 0.000 \\
\hline MPT /\#/ 1 & 30 & 15.26 & 15.01 & 3.41 & \\
\hline MPT /\#/ 2 & 30 & 16.37 & 15.24 & 4.63 & 0.090 \\
\hline
\end{tabular}

Wilcoxon test $(p<., 05)$. Legend: $S D=$ standard deviation; MPT = Maximum Phonation Times 1 and 2 - Traditional orientation 
Table 3 (shown below) compares the two groups (CG and SG) regarding the results obtained for MTP in emissions of the first and second instants. When comparing these two groups based on the emissions of the first instant, there are no statistically significant differences between them. However, when the emissions of the second instant are compared (guidance on airflow control versus traditional orientation), there are differences in the emissions of /i/, /u/, mean of vowels, /s/, /z/ and number counting, which indicates that the request for airflow control promotes greater modifications of MPT than the repeating procedure of a task under the same orientation, as did the CG subjects.

Table 3. Comparison between the study (SG) and control (CG) groups regarding the results of Maximum Phonation Time in the two instants of emissions

\begin{tabular}{|c|c|c|c|c|c|c|c|c|c|}
\hline \multirow{2}{*}{ Emissions } & \multicolumn{4}{|c|}{ Control group } & \multicolumn{4}{|c|}{ Study group } & \multirow[b]{2}{*}{$\mathbf{p}$} \\
\hline & $\mathbf{n}$ & Mean & Median & SD & $\mathbf{n}$ & Mean & Median & DP & \\
\hline MPT /a/ emission $1^{\star \star}$ & 30 & 12.98 & 12.97 & 3.22 & 30 & 11.85 & 10.62 & 3.68 & 0.21 \\
\hline MPT /a/ emission 2** & 30 & 13.66 & 13.5 & 3.59 & 30 & 15.56 & 15.23 & 4.64 & 0.08 \\
\hline MPT /i/ emission $1^{* *}$ & 30 & 14.05 & 13.37 & 3.56 & 30 & 12.55 & 12.64 & 3.37 & 0.09 \\
\hline MPT /i/ emission 2** & 30 & 14.73 & 13.17 & 4.84 & 30 & 18.77 & 17.82 & 5.56 & 0.00 \\
\hline MPT /u/ emission $1^{\star * *}$ & 30 & 13.81 & 12.54 & 3.81 & 30 & 13.1 & 12.22 & 4.08 & 0.49 \\
\hline MPT /u/ emission $2^{* \star}$ & 30 & 15.54 & 14.47 & 4.54 & 30 & 18.13 & 17.3 & 5.06 & 0.05 \\
\hline Mean vowels emission 1 * & 30 & 13.61 & 13.31 & 3.1 & 30 & 12.5 & 12.04 & 3.22 & 0.17 \\
\hline Mean vowels emission $2^{*}$ & 30 & 14.62 & 14.08 & 4.03 & 30 & 17.52 & 16.35 & 4.71 & 0.01 \\
\hline MPT /s/ emission 1** & 30 & 13.05 & 11.95 & 4.19 & 30 & 13.77 & 12.34 & 5.76 & 0.62 \\
\hline MPT /s/ emission 2** & 30 & 14 & 12.61 & 4.62 & 30 & 18.33 & 17.52 & 8.08 & 0.00 \\
\hline MPT /z/ emission $1^{\star * *}$ & 30 & 12.6 & 11.46 & 4.85 & 30 & 12.45 & 12.3 & 4.48 & 0.73 \\
\hline MPT /z/ emission 2** & 30 & 14.52 & 11.61 & 5.76 & 30 & 18 & 17.03 & 5.81 & 0.01 \\
\hline $\mathrm{s} / \mathrm{z}$ ratio $1^{* \star}$ & 30 & 1.05 & 1.02 & 0.36 & 30 & 1.12 & 1.1 & 0.36 & 0.42 \\
\hline s/z ratio $2^{\star *}$ & 30 & 0.96 & 0.95 & 0.27 & 30 & 1.02 & 1 & 0.29 & 0.05 \\
\hline Number counting $1^{* *}$ & 30 & 15.26 & 15.01 & 3.41 & 30 & 16.37 & 16.32 & 5.44 & 0.61 \\
\hline Number counting $2^{* \star}$ & 30 & 16.37 & 15.24 & 4.63 & 30 & 19.89 & 18.97 & 5.86 & 0.01 \\
\hline
\end{tabular}

Student's T test* and Mann-Whitnney **. SD $=$ Standard deviation $(p<0.05)$

CG: 1 and 2 - Traditional orientation

SG: 1 - Traditional orientation; 2 - Orientation with airflow control

MPT = Maximum Phonation Time

\section{DISCUSSION}

As shown in Table 1, when comparing the first instant of the emissions (traditional) with the second ones (airflow control) in the SG, a significant increase in the obtained MPT values under the second instant of emission is observed. Regarding the guidance of airflow control on emissions, no other studies were found that have done similar analyzes that could corroborate this finding. However, a study involving children found that when the speech-language pathology guidance was given with visual support, the obtained MPT values were higher in comparison to the group of children who received guidance this kind of support ${ }^{15}$.

One of the hypotheses raised for the results obtained in the SG (Table 1) is that, when requesting that the subject perform the airflow control, she can have more concentration, that is, she has a higher focus on the requested task. Another hypothesis is that the subject may have used resources that helped her during the performance of the speech task, such as using different vocal tract adjustments in an attempt to prolong the emission, although this has not been evaluated. It is worth mentioning that the subjects were instructed to perform normal phonation with no effort, and no changes were observed in body tension during the emissions in the two ways of guidance.

The CG subjects were oriented in two instants to emit sounds in MPT and in the traditional form, and most of the obtained samples remained unchanged (Table 2). Only two of the evaluated emissions showed differences between the two execution instants - $(/ \mathrm{u} /$ e $/ z /)$. Some studies have concluded that it is not 
necessary to extract more than one emission in MPT, since the values are similar regardless of the number of samples ${ }^{16,17}$. However, in this case, it was important to have the values from other emissions with no significant difference between the instants to corroborate the hypothesis that these two differences in the two instants of the emissions in MPT in the CG occurred at random. We emphasize that the CG was adopted in this study in order to try to minimize the bias of a possible change in the obtained values by not a modification related to the clinician's instruction but to the cumulative effect of the use of voice in both instants.

In Table 3, there is a comparison between the groups (CG and SG) regarding the results of MPT obtained in the two instants of the emissions. When the $C G$ and $S G$ are compared at the first instant of the emissions, in which both performed the traditional orientation, there are no statistical differences for MPT. However, significant differences between the times of both groups are observed for each of the evaluated parameters when comparing $C G$ and $S G$ in the second instant of the emissions (when they undergo different orientations). With this finding, it can be said that the guidance given by the speech-language pathologist was fundamental for the groups to have this difference since they were very homogeneous, that is, they had the same number of participants, age range, gender, and the same human position during the emission. Although the CG (Table 2) increased the time of three emissions, when it was compared with the SG (Table 3 ), it is observed that the increase of the emissions in the $S G$ is much higher than that.

By means of this study, it was possible to observe that the obtained values are close to the normality described in the literatur ${ }^{18}$ when the subject is oriented to control the airflow during the emissions as can be evidenced in the values found after the orientation of airflow control in the SG: /a/ $15.56 \mathrm{~s}$; /i/ $18.77 \mathrm{~s}$; /u/ $18.13 \mathrm{~s} ; / \mathrm{s} / 18.33 \mathrm{~s} ; / \mathrm{z} / 18 \mathrm{~s}$; and number counting $19.89 \mathrm{~s}$ (Table 3). However, the values obtained fall short of what are expected when traditionally oriented as in studies found in the literature $e^{3,10,19,20}$. Thus, we questioned if other studies conducted with traditional orientation for extracting the MPT ${ }^{3,4,18-26}$ would have values different from those obtained here in case they had been performed under the same conditions but requesting the airflow control during the emissions.

The work of Miglioranzi et al. ${ }^{4}$ aimed to verify the vital capacity and MPT values of voiceless /e/ and /s/ for adult women, establishing the sample profile and comparing it with the proposed normality standard. The results obtained in such study were lower than what is proposed in the literature ${ }^{18}$, with the average of the MPTs from fricative /s/ and voiceless /e/ being around 11 seconds when the expected value for vocally healthy women is 14 seconds. If the Miglioranzi et al.' study ${ }^{4}$ used voiceless sounds, the idea would be to reach the highest MPT since they do not promote glottal closure and thus only the respiratory and vital capacity characteristics were analyzed. However, in the present study, which adopted similar population and inclusion and exclusion criteria, due to the demand for airflow control, much higher MPT averages in the vowels were obtained than those from the aforementioned study, which reinforces the idea of that the way the task is executed can make a big difference in the obtained values.

Similarly, another study ${ }^{11}$ that aimed to verify the MPT extraction reliability of the sustained vowel /a/ in subjects with no vocal complaints also presented lowerthan-expected MPT values for healthy adult women, around 12 seconds, using the same form of traditional orientation carried out in the present study. Reduced MPT in women of a choir without vocal complaints has also been observed in another study ${ }^{24}$, but the authors have not reported how the guidance given by the speech-language pathologist was performed.

Thus, the results of the present study demonstrated that the way subjects/patients have been guided in the extraction of temporal measures of voice, that is, the type of orientation influences the obtained values. In this study it was possible to verify that the obtained values are equal to those of the normality when the subject is guided to control the airflow during the emission. Therefore, it can be said that the way the speech-language pathologist guides subjects in extracting MPT is one of the variables that can interfere with the expected results for the test. It is noteworthy that there are other variables (already mentioned in this study) that may influence the extraction of the phonatory measurements.

Additionally, the findings of this study lead us to reflect on the MPT normality value according to the reference of Behlau and Pontes ${ }^{18}$, in which values of 14 seconds are presented for women and 20 seconds for men. It is worth mentioning that these values were obtained based on a survey carried out with the population of the city of São Paulo, and no detailed methodological data about the data gathering were found, particularly related to the instruction given to the 
subject, which hindered the comparison with the values obtained in the present research.

Finally, some limitations that this study presents are pointed out. One is the reduced number of subjects. Another limitation was the studied age range: the study was performed over a population with 17 to 23 years old, and it was noted the importance of including a larger age range. Characteristics such as height, body mass and sports practice were not controlled in this study since the objective was to compare the subject with herself, at two different instants, through dependent tests. Therefore, the objective of the present study allowed for a certain heterogeneity regarding these variables, which can be known to influence the MPT results depending on the analysis being sought.

In addition to the study limitations, it is also proposed ideas for future research as well as works that can better investigate the MTP normality in both vocally healthy subjects and those with vocal alterations. It would also be interesting to perform the airflow guidance with voice professionals, since they are expected to have good MPT. The question that would lead such research is: when guiding voice professionals to control the airflow emission, would they present differences in the maximum phonatory times when compared to non-voice professionals? Another proposal is related to the number of subjects, a survey that would include a larger number of people could contribute to the confirmation of the hypotheses raised in this study. Finally, perform the same work with males, compare the obtained values between men and women, and relate them to the normality values described in the literature, as well as verifying the MPT values in subjects with vocal alterations under the two forms of orientation.

\section{CONCLUSION}

The method in which the speech-language pathologist guides the production of the maximum phonation times, requesting the maximum control of the airflow from the subject, modifies the result of the extraction of voice temporal measurements, and should be considered in daily vocal clinical practice.

\section{REFERENCES}

1. Rossi DC, Munhoz DF, Nogueira C R, Oliveira TCM, Britto ATBO. Relação do pico de fluxo expiratório com o tempo de fonação em pacientes asmáticos. Rev. CEFAC. 2006;8(4):509-17.
2. Behlau M, Madazio G, Feijó D, Pontes $P$. Avaliação de voz. In: Behlau M (org). Voz: o livro do especialista. Rio de Janeiro: Revinter. 2001. p. 85-245.

3. Miglioranzi SL, Cielo CA, Siqueira MA. Capacidade vital e tempos máximos de fonação de /e/ áfono e de /s/ em mulheres adultas. Rev. CEFAC. 2012;14(1):97-103.

4. Beber BC, Cielo CA, Siqueira MA. Lesões de borda de pregas vocais e tempos máximos de fonação. Rev. CEFAC. 2009;11(1):134-41.

5. Fabron EMG, Sebastião LT, Oliveira GAG, Motonaga SM. Medidas da dinâmica respiratória em idosos participantes de grupos de terceira idade. Rev. CEFAC. 2011;13(5):895-901.

6. Steffen LM, Moschetti MB, Steffen N, Hanayama EM. Paralisia unilateral de prega vocal: associação e correlação entre tempos máximos de fonação, posição e ângulo de afastamento. Rev Bras Otorrinolaringol. 2004;70(4):450-5.

7. Speyer R, Bogaardt HC, Passos VL, Roodenburg NP, Zumach A, Heijnen MA et al. Maximum phonation time: variability and reliability. $\mathrm{J}$ Voice. 2010;24(3):281-4.

8. Rodrigues ZR, Behlau M. Comparação dos tempos máximos de fonação em emissão sustentada de vogais e em fala encadeada em diferentes categorias diagnósticas. In: Behlau M, Gasparini G(org). A voz do especialista. Vol III. Rio de Janeiro: Revinter, 2006. Cap 30, p. 381-90.

9. Kurtz LO, Cielo CA. Tempos máximos de fonação de vogais em mulheres adultas com nódulos vocais. Pró-Fono R Atual Cientif. 2010;22(4):451-4.

10. Carréra CMD, Araújo ANB, Lucena JA. Correlation between slow vital capacity and the maximum phonation time in elderly. Rev. CEFAC. 2016; 18(6):1389-94.

11. Englert M, Mesquita LG, Azevedo R. Comparison of methods to extract the maximum phonation duration in individuals without vocal complaints. Rev. CEFAC. 2014 ;16(5):1615-20.

12. Johnson AM, Goldfine A. Intrasubject reliability of maximum phonation time. J Voice. 2016; 30(6):775. e1-775.e4.

13. Frigo LF, Cielo CA, Lima JPM, Braz MM. Body power center, maximum phonation time and sound pressure of healthy women. Audiol. Commun. Res. 2017;22: e1685. [ahead of print].

14. Pascotini FS, Haeffner LSB, Cielo CA. Forced vital capacity and maximum phonation time compared 
to waist circumference and nutritional status of children. Rev. CEFAC. 2016;18(4):915-22.

15. Paes SM, Azevedo RR. Efeito do apoio visual nas medidas de tempo máximo fonatório em crianças. Distúrb Com. 2010;22(2):127-32.

16. Cunha LJ. Influência da posição corporal no resultado da extração de medidas temporais da voz. [Trabalho de conclusão de curso]. Irati (PR): Universidade Estadual do Centro-Oeste; 2015.

17. Shinoda T, Kanai M, Nakamura R, Murata S, Saito $\mathrm{T}$, Sawa $\mathrm{R}$ et al. The relative and absolute reliability of maximum phonation time in communitydwelling Japanese people. Aging Clin Exp Res. 2016;29(4):781-6. DOI 10.1007/s40520-016-0573-y

18. Behlau M, Pontes P. Avaliação e Tratamento das Disfonias. São Paulo: Lovise, 1995.

19. Christmann MK, Scherer TM, Cielo CA, Hoffmann CF. Tempo máximo de fonação de futuros profissionais da voz. Rev. CEFAC. 2012;15(3):622-30.

20. Mendonça RA, Sampaio TMM, Provenzan OL. Medida do tempo máximo de fonação de professoras do Município de Niterói/RJ. Rev. CEFAC. 2012;14(6):1204-8.

21. Solomon NP, Garlitz SJ, Milbrath RL. Respiratory and laryngeal contributions to maximum phonation duration. J Voice. 2000;14(3):331-40.

22. Cielo CA, Cappellari M. Tempo máximo de fonação de crianças pré-escolares. Rev Bras Otorrinolaringol. 2008;74 (4):552-60.

23. Cerceau JSB, Alves CFT, Gama ACC. Análise acústica da voz de mulheres idosas. Rev. CEFAC. 2009;11(1):142-9.

24. Vieira RH, Gadenz CD, Cassol M. Longitudinal study of vocal characterization in choral singing. Rev. CEFAC. 2015;17(6):1781-91.

25. Aghajanzadeh M, Darquie A, Dabirmoghaddam $P$, Salehi A, Rahgozar M. The relationship between the aerodynamic parameters of voice and perceptual evaluation in the iranian population with or without voice disorders. J Voice. 2016;31(2):250e9-e15.

26. Liang FY, Huang XM, Chen L, Huang YZ, Zang $\mathrm{XY}, \mathrm{SU} \mathrm{JH}$ et al. Voice therapy effect on mutational falsetto patients: a vocal aerodynamic study. J Voice. 2016;31(1):114e1-e5. 